showed but a poor increase in yield (its merits were made clear in later trials under improved conditions). A belief had therefore grown up that the attainable yield of rain-grown cotton in the area was decidedly lower than that for other African territories.

Rainfall (total and effective) appeared to be the dominating factor for yield, and experiments were made during 1957-59 to assess its influence. From meteorological records and observations, 40 in. was deduced as the expected ( $1: 1$ chance) annual rainfall, $27 \cdot 4 \mathrm{in}$. of which would come after July 1 ; and under local conditions a crop of cotton would need about 25 in. of rain in the growing season if growth was not to be limited by soil moisture (July 1 is recommended as the sowing dato for cotton, as the earliest which allows food crops to be planted first). What happens to rain after reaching the soil and how control of this influences yield were the primary issues in the field experiments.

Surface 'capping' through heavy rain, to which the local soils are specially prone, was shown to be largely controllable by timely hoeing and by mulching, entry of rain into the soil being thus greatly increased. The land is ridged for cotton and other crops, and it was found that here, as elsewhere, water conservation could be improved by 'tying' the ridges with small bunds at intervals along the furrows. In dry years this considerably increased yield but depressed it in wet years. These effects were clearly interpreted by soil-moisture profiles.

The effects of varying degrees of these controls having thus been measured, field trials were arranged, having in mind steps which could be fitted into peasant practice. A light mulching, in the furrow bot. toms only, proved effective, and by slitting the furrow bottom and working a small amount of mulch into the slit the effect was enbanced. Tying alternate ridges only worked well, and avoided yield depression through standing water in wet years. Groundnut shell, dead grass and chopped Sorghum stalks made good mulches, the shell being best. By preparing the land for sowing at the onset of the rains, instead of just before sowing, which is local practice, cotton yields were raised by 15 to 20 per cent in two trials. Increased penetration and retention of rain had evidently been secured. Good response to fertilizers was obtained where tied ridges and mulch were also used.

The practical inference was clear-fertilizers, insecticidal protection, improved varieties and other betterments are repaid only when water conservation is amply ensured and this is practicable at peasant husbandry level. To drive the lesson home, cotton was grown on a half-acre plot for four years running in which rainfall was $55,35,42$ and 43 in. Yields were all of the order of $2,000 \mathrm{lb}$. of seed cotton an acre, which is good for rain-grown cotton anywhere and excellent in comparison with any other part of Africa. Moreover, picking was ended by Christmas whereas it dawdled on for another 2-3 months on other plots.

This successful husbandry investigation is of more than local and immediate value. It is part of the widespread studies of rainfall, soil moisture and crop water needs carried out by the Empire Cotton Grow ing Corporation. The basic work is done at its Central Research Station, Namulonge, Uganda. All this work deals not with cotton alone but also in conjunction with the customary food crops of cotton growers. Agriculture in general is thus benefited in cotton-producing countries. Moreover, the practical problems centring on rainfall are becoming so defined and resolved as to enable their deeper, physiological study to be effectively opened up. Plant breeding, also, gains a clearer sense of direction.

\section{F. L. Engledow}

\title{
RADIOMETRIC AND PHOTOMETRIC STANDARDS
}

$\mathrm{T}$ WO recent publications in the series Notes on Applied Science of the National Physical Laboratory, Teddington, illustrate some of the activities of the Light Division of the Laboratory.

No. 23 in the series ${ }^{1}$, Radiometric Standards and Measurements, by E. J. Gillham, deals with the methods used at the Laboratory for the measurement of ultra-violet, visible and infra-red radiation. The contents consist of three main sections devoted to the measurement of total radiation, the measurement of monochromatic radiation, and the absolute measurement of radiation, respectively. Total radiation is usually more intense than monochromatic radiation and therefore can be measured more easily, but the total energy content of a bearn of radiation is often of less practical significance. An instrument for measuring total radiation must be equally sensitive to radiation at all wave-lengths, and the only means of converting radiation into another form of energy with predictable efficiency over the whole wavelength range is by absorption at a blackened surface, that is, to use a thermal dotector. Fortunately, blacks with an absorption factor of 95 per cent or more over the wholo spectral range of interest aro available, and consequently thermal detectors with an error due to selectivity of not more than 2 or 3 per cent can be obtained. The type of thermal detector commonly used is the thermopile, and in the booklet the Moll thormopile, which has stable characteristics and which forms a very useful working standard for measuring radiation or for calibration of other radiation detectors, is described in some detail. A set of six Moll thermopiles is maintained at tho National Physical Laboratory for calibration purposes. The methods used for the intercomparison of thermopiles and for the accurate measurement of the selectivity of a thermopile using a Callender radiobalance and three different sources of radiation are discussed.

To illustrate the problems encountered in the measurement of monochromatic radiation a description is given of a routine test undertaken at the Laboratory to determine the special sensitivity of a photoemissive cell, in the $0 \cdot 25-0 \cdot 7 \mu$ wave-length range. The optical arrangements and apparatus required for the measurement of the spectral sensitivity, and also the absolute sensitivity of the photocell, are given. For the absolute measurement of radiation a thermal detector in which the target is provided with a resistance element or other means for supplying a measurable amount of electrical power is recommended. At the National Physical Laboratory the absolute radiometer used is the Guild drift radiometer. It is of the compensated type with 
two similar receivers, the front one of which is exposed to the radiation. The target consists of a massive copper disk $4.5 \mathrm{~cm}$. in diameter and $0.5 \mathrm{~cm}$. thick to ensure temperature uniformity. Thermocouples are attached at a number of points in order to average the rise in temperature. The electrical heating element is cemented to the front disk on the side exposed to the radiation. The cycle of operations and the practice carried out in the Laboratory for the calibration of working-standard thermopiles against the Guild radiometer with a radiation source, consisting of a 1,000-W. tungsten lamp operated at a colour temperature of $2,850^{\circ} \mathrm{K}$., together with water filter and heat-absorbing glass to absorb radiation of a wave-length longer than $1 \mu$, are explained in detail.

The second booklet, No. 24 (ref. 2), is concerned with photometric standards and the unit of light. The development of light sources from the early nineteenth century and the evolution of the present primary standard, with the internationally accepted unit of luminous intensity, the candela, are discussed, followed by a detailed description of the procedures carried out at the National Physical Laboratory with regard to the arrangement of the primary standard, ond calibration of secondary standards of luminous intensity and luminous flux. Finally, the present international situation with regard to intercomparisons of photometric scales is reviewed, and a table is given showing the relative magnitudes of the candela $\left(2,042^{\circ} \mathrm{K}\right.$.) as found in the most recent determinations (up to 1957) at various national laboratories. The monograph can be recommended as a comprehensive and instructive statement of photometric standards and light sources, and should be of value to all concerned with illumination. S. WEINTrouB

${ }^{1}$ Department of Scientific and Industrial Research: National Physical Laboratory. Notes on Applied Science, No. 23: Radiometric Standards and Mecsurements. F. J Gillham. $\mathrm{Pp}$. iv +23 , (London: H.M.S.O., 1961.) 18. $9 d$. net.

2 Department of Scientifle and Industrial Research: National Physical Laboratory. Nutes on Applied Science No. 24: Photometric Standards and the Unit of Light. J. S. Preston. Pp. iv +32+ 4 plates. (London: H.M.S.O., 1961.) 38 . net.

\section{GEOLOGY OF BROWN CLEE HILL AND THE ADJACENT AREA}

\begin{abstract}
THE Old Red Sandstone of Brown Clee Hill and the Adjacent Area*, recently issued by the British Museum (Natural History), is an important paper as it deals with a classic area in which is displayed the most complete sequence of Old Red deposits of the Anglo-Welsh development. In the first quarter of the century Wickham King established a general stratigraphical succession for that development, which he based to a large extent on his findings in the Brown Clee district, but his support ing palæontological evidence was too meagre and scattered to provide really convincing fossil zones. At that time too many of the forms had been inadequately described or named from fragments. King's work, however, generated a stimulus that has led to a revolution in our knowledge of the British Old Red ostracoderm faunas. This has been the result of systematic collecting and accurate description. The latter we owe chiefly to the senior author, Dr. E. I. White, and Part 2 of the present paper is his latest contribution to the subject. While our knowledge of the fossils has been gradually accumulating, the palæontologist has had, to a great extent, to rely on King's stratigraphical conclusions, which were not always based on reliable mapping.
\end{abstract} * Bulletin of the British Museum (Natural History). Geology.
Vol. 5, No. 7: The Old Red Sandstone of Brown Clee Hill and the Vol. 5, No. 7: The Old Red Sandstone of Brown Clee Hill and the Adjacent Area. 1: Stratigraphy. By Harold William Ball and David Lawrence Dineley. 2: Palæontology By Errol Ivor White. Pp 1961.) 70 s.
In the present case the two junior authors have presented an excellent map based on accurate 6 -in. survey and elaborate collecting, which have enabled them to determine the range of the fossils with considerable accuracy. For the Downtonian Series, they have taken advantage of much recent palæontological work; and the zones for this series can now be regarded as well established, and their evidence as merely confirming conclusions reached previously in this and other areas. But for the desperately barren Dittonian and Clee Series, their painstaking fie'd-work has supplied Dr. White with material, by which broad zones can now be defined with some exactness.

Part 1, devoted to the stratigraphy, includes interesting discussions concerning the geographical conditions governing sedimentation, the ecology of the fossiliferous 'pockets', the so-called Psammosteus Limestone (which has never yielded a fossil, let alone a Psammosteus), and foreign pebbles in the conglomerates; but its main significance is the correlation of the fossils with the stratal succession, and the determination of the range of each important species. A valuable feature is a list of more than a hundred localities with the fauna discovered at each.

Part 2 is descriptive of a number of new species and varieties illustrated by 60 text figures and 16 plates. Of particular value are the new forms discovered by the authors and others in the Clee Series and in the unconformable upper Old Red beds (the Farlow Sandstone Series).
L. J. WILLS

\section{FIRE RESEARCH 1960}

$\mathrm{T}$ HE recently issued annual report of the Joint Fire Research Organization * records the bringing into use, during 1960 , of new buildings providing $30,000 \mathrm{sq}$. ft. of permanent floor area for the continued prosecution of fire research (see Nature, 189, 105; 1961).

* Department of Scientific and Industrial Research and Fir Offices' Committee Joint Fire Research Organization. Fire Research, 1960: Report of the Fire Research Board with the Report of the Director of Fire Research. Pp. viii $+67+12$ plates. (London: H.M.S.O., 1961.) 58. 6 d. net.
Among the many investigations described, that which focused attention on the behaviour in draughts of oil heaters of the drip-feed radiant type has doubtless aroused the greatest public interest. The relatively new and unique wind-tunnel facilities of the Fire Research Station permitted an expeditious study of this problem, followed, within the year under review, by the publication of a report and a new British Standard and, finally, by the introduction of appropriate legislation. 